\title{
Article
}

\section{Obesity and Bone Loss at Menopause: The Role of Sclerostin}

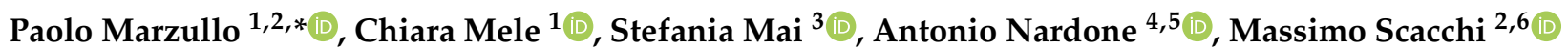 \\ and Gianluca Aimaretti ${ }^{1}$ (D)
}

1 Department of Translational Medicine, University of Piemonte Orientale, 28100 Novara, Italy; chiara.mele1989@gmail.com (C.M.); gianluca.aimaretti@med.uniupo.it (G.A.)

2 Istituto Auxologico Italiano, IRCCS, Division of General Medicine, S. Giuseppe Hospital, 28824 Piancavallo, Italy; massimo.scacchi@unimi.it

3 Laboratory of Metabolic Research, Istituto Auxologico Italiano, IRCCS, S. Giuseppe Hospital, 28824 Piancavallo, Italy; s.mai@auxologico.it

4 Department of Clinical-Surgical, Diagnostic and Pediatric Sciences, University of Pavia, 27100 Pavia, Italy; antonio.nardone@icsmaugeri.it

5 Neurorehabilitation and Spinal Unit, Istituti Clinici Scientifici Maugeri SPA SB, Institute of Pavia, IRCCS, 27100 Pavia, Italy

6 Department of Clinical Sciences and Community Health, University of Milan, 20122 Milan, Italy

* Correspondence: paolo.marzullo@med.uniupo.it

Citation: Marzullo, P.; Mele, C.; Mai, S.; Nardone, A.; Scacchi, M.;

Aimaretti, G. Obesity and Bone Loss at Menopause: The Role of Sclerostin. Diagnostics 2021, 11, 1914. https:// doi.org/10.3390/diagnostics11101914

Academic Editors: Alessandro de Sire, Elisabetta Ferraro and

Massimiliano Leigheb

Received: 17 September 2021

Accepted: 11 October 2021

Published: 16 October 2021

Publisher's Note: MDPI stays neutral with regard to jurisdictional claims in published maps and institutional affiliations.

\section{Copyright: (c) 2021 by the authors.} Licensee MDPI, Basel, Switzerland. This article is an open access article distributed under the terms and conditions of the Creative Commons Attribution (CC BY) license (https:// creativecommons.org/licenses/by/ $4.0 /)$.

\begin{abstract}
Background. Peripheral fat tissue is known to positively influence bone health. However, evidence exists that the risk of non-vertebral fractures can be increased in postmenopausal women with obesity as compared to healthy controls. The role of sclerostin, the SOST gene protein product, and body composition in this condition is unknown. Methods. We studied 28 severely obese premenopausal (age, $44.7 \pm 3.9$ years; BMI, $46.0 \pm 4.2 \mathrm{~kg} / \mathrm{m}^{2}$ ) and 28 BMI-matched post-menopausal women (age, $55.5 \pm 3.8$ years; BMI, $46.1 \pm 4.8 \mathrm{~kg} / \mathrm{m}^{2}$ ) thorough analysis of bone density (BMD) and body composition by dual X-ray absorptiometry (DXA), bone turnover markers, sclerostin serum concentration, glucose metabolism, and a panel of hormones relating to bone health. Results. Postmenopausal women harbored increased levels of the bone turnover markers CTX and NTX, while sclerostin levels were non-significantly higher as compared to premenopausal women. There were no differences in somatotroph, thyroid and adrenal hormone across menopause. Values of lumbar spine BMD were comparable between groups. By contrast, menopause was associated with lower BMD values at the hip $(p<0.001)$, femoral neck $(p<0.0001)$, and total skeleton $(p<0.005)$. In multivariate regression analysis, sclerostin was the strongest predictor of lumbar spine BMD $(p<0.01)$, while menopausal status significantly predicted BMD at total hip $(p<0.01)$, femoral neck $(p<0.001)$ and total body $(p<0.05)$. Finally, lean body mass emerged as the strongest predictor of total body BMD $(p<0.01)$. Conclusions. Our findings suggest a protective effect of obesity on lumbar spine and total body BMD at menopause possibly through mechanisms relating to lean body mass. Given the mild difference in sclerostin levels between pre- and postmenopausal women, its potential actions in obesity require further investigation.
\end{abstract}

Keywords: obesity; menopause; osteoporosis

\section{Introduction}

Despite being acknowledged as beneficial to bone mineral density (BMD) due to the mechanical loading effect of weight excess [1], obesity is emerging as a potential detrimental factor for bone health, particularly appendicular bones [2]. Studies in adolescents and adults pinpointed the negative effects of body fat excess on bone strength [3-5] and cortical rearrangement through insulin resistance [6]. In single-center analysis, osteoporosis was associated with obesity in one out of three women [7], while prospective studies found that nearly one out of four postmenopausal women with fractures presented with obesity, with obesity acting as the dominant risk factor for ankle and upper leg fractures [8]. In 
parallel, obese postmenopausal women were found to harbor reduced femoral neck BMD and increased risk of non-vertebral fragility fractures [9].

Reid [10] proposed the common stromal cell origin of osteoblasts and adipocytes as a possible link between adipose tissue and bone. An interaction between obesity, menopause and bone metabolism exists [11] and involves several potential mechanisms: menopauses promotes visceral fat accumulation [12] and sarcopenia [13], which compromise the mechanical loading effect [14]; fat accumulation lowers vitamin D levels with secondary hyperparathyroidism, which results in bone loss and accelerated osteoporosis [15]; obesity impacts endocrine signals active on the bone, such as the somatotroph [16], adrenal [17] and thyroid axis [18]; type 2 diabetes mellitus (T2DM) impairs the strength of femoral neck relative to mechanical load [19] and enhances the fracture risk [20]. It is noteworthy that leptin and other adipokines secreted from the adipose tissue can modulate bone cells through major inhibition of bone remodeling, whereas molecules activating the peroxisome proliferator-activated receptor- $\gamma$ can drive mesenchymal stem cell differentiation from osteoblastic towards adipocyte lineage [21]. It is known that obesity is characterized by leptin resistance, which has been linked to decreased bone mass, as it happens in case of extreme leanness with hypoleptinemia [22]. Moreover, insulin partakes in the feedback loop between pancreas and osteoblasts [23], enhances bone resorption and promotes the decarboxylation of osteocalcin, a bone-derived protein that is capable of regulating insulin release, insulin sensitivity, and fat mass accrual [24]. Finally, the insulin-sensitizing adipocyte-derived protein adiponectin can modulate bone remodeling via osteocalcin as well [25].

Among the intermediate pathways, the Wnt/ $\beta$ catenin signaling pathway is known to stimulate the expansion of osteoprogenitor cells and suppress apoptosis of mature osteoblasts and osteoclastogenesis in response to biomechanical stress [26]. Wnt also plays a role in adipocyte differentiation and pathogenesis of metabolic diseases [27]. Importantly, Wnt is antagonized by the osteocyte-secreted product of the SOST gene, sclerostin $[28,29]$. Sclerostin predicts bone loss in relation to age, gender and menopause [30], prolonged immobilization [31], and postmenopausal hip fracture risk [32]. Studies also emphasized the potential role of sclerostin in relation to adiposity and type 2 diabetes mellitus [33,34]. While no difference in serum sclerostin was documented in obese as compared to control women [35], serum sclerostin was found to be negatively associated with insulin sensitivity in obese but not lean subjects, suggesting a potential role for the Wnt/ $\beta$-catenin pathway in regulating insulin sensitivity in obesity [36]. Moreover, sclerostin has been found to increase in states of unloading and to possibly mediate the changes in bone metabolism associated with weight loss and exercise [37], and population studies reported a negative association between sclerostin and skeletal muscle mass after adjusting for confounding factors, including age, sex, bone mineral content, and total body fat mass [38].

Based on the peculiar postmenopausal osteoporosis risk in obesity and the involvement of the Wnt pathway in the link between osteogenesis and adipogenesis, we sought to explore the role of circulating sclerostin on skeletal bone in pre- and post-menopausal women in relation to body composition, glucose homeostasis and a comprehensive set of bone/adipose tissue markers in women with obesity. Secondly, we aimed to assess the control operated by these factors on circulating sclerostin to profile its determinants in the obese state.

\section{Materials and Methods}

\subsection{Study Population}

This study included 56 women with severe obesity (BMI $>35 \mathrm{~kg} / \mathrm{m}^{2}$ ) enrolled as premenopausal $(n=28)$ and postmenopausal subjects $(n=28)$ (Table 1$)$. Menopause was defined as cessation of menstrual bleeding for at least 12 months together with low estradiol and high FSH levels. In our postmenopausal subgroup, mean menopause duration was $5.1 \pm 5.1$ years. All participants enrolled in the study had long-lasting obesity ( $>10$ years), and obesity was defined as having a BMI $>30 \mathrm{~kg} / \mathrm{m}^{2}$. The exclusion criteria for the study 
included: menarche > 16 years; previous hysterectomy, ovarian surgery, sex hormone replacement treatment, menopause $<45$ years; osteoporosis treatment; previous diagnosis of type 1 diabetes mellitus (T1DM) and T2DM, autoimmune disorders affecting bone metabolism; chronic steroid, heparin or anti-convulsant therapy; evidence of spontaneous fractures, osteogenesis imperfecta, family history of severe osteoporosis malnutrition, malabsorption, chronic liver or kidney disease; less than one alcoholic drink reported per day and smoking habit. Each participant was admitted to the study as part of a regular workup of obesity and its complications, and enrolled after signing an informed consent. The study was conducted in accordance with the Declaration of Helsinki, and the protocol was approved by the Ethics Committee of Istituto Auxologico Italiano.

Table 1. Anthropometric and biochemical parameters measured in the study groups. Significance was calculated by two-tailed unpaired Student's $t$-test. For significance: ${ }^{*} p<0.05 ;{ }^{* *} p<0.01$; $* * * p<0.001$.

\begin{tabular}{ccc}
\hline Parameters & $\begin{array}{c}\text { Premenopausal Women } \\
\mathbf{( N = 2 8 )}\end{array}$ & $\begin{array}{c}\text { Postmenopausal Women } \\
(\mathbf{N}=\mathbf{2 8})\end{array}$ \\
\hline Age $(\mathrm{years})$ & $44.7 \pm 3.9$ & $55.5 \pm 3.8^{* * *}$ \\
Weight $(\mathrm{kg})$ & $117.2 \pm 9.7$ & $113.7 \pm 13.6$ \\
Height $(\mathrm{cm})$ & $158.8 \pm 7.2$ & $157.0 \pm 6.3$ \\
BMI $\left(\mathrm{kg} / \mathrm{m}^{2}\right)$ & $46.0 \pm 4.2$ & $46.1 \pm 4.8$ \\
Glucose $(\mathrm{mg} / \mathrm{dL})$ & $102.0 \pm 16.0$ & $111.9 \pm 32.0$ \\
Post-OGTT glucose $(\mathrm{mg} / \mathrm{dL})$ & $154.7 \pm 62.2$ & $146.6 \pm 54.6$ \\
Insulin $(\mathrm{mIU} / \mathrm{mL})$ & $14.8 \pm 8.4$ & $14.1 \pm 8.5$ \\
Post-OGTT insulin $(\mathrm{mIU} / \mathrm{mL})$ & $103.6 \pm 82.7$ & $88.1 \pm 55.4$ \\
HbA1c $(\%)$ & $6.1 \pm 0.5$ & $6.5 \pm 1.4$ \\
HOMA-IR & $3.8 \pm 2.4$ & $3.8 \pm 2.3$ \\
Leptin $(\mu \mathrm{g} / \mathrm{L})$ & $75.5 \pm 21.8$ & $78.8 \pm 29.7$ \\
Adiponectin $(\mu \mathrm{g} / \mathrm{L})$ & $8.1 \pm 3.0$ & $11.2 \pm 5.3 * *$ \\
FSH $(\mu \mathrm{g} / \mathrm{L})$ & $6.5 \pm 5.4$ & $45.7 \pm 22.3^{* * *}$ \\
LH $(\mu \mathrm{g} / \mathrm{L})$ & $5 \pm 4.3$ & $25.9 \pm 10.7 * * *$ \\
PRL $(\mu \mathrm{g} / \mathrm{L})$ & $21.5 \pm 11.3$ & $13.4 \pm 8.8^{*}$ \\
Estradiol $(\mu \mathrm{g} / \mathrm{L})$ & $110.1 \pm 80$ & $40.2 \pm 12.3^{* * *}$ \\
Testosterone $(\mu \mathrm{g} / \mathrm{L})$ & $1.1 \pm 0.5$ & $1.2 \pm 0.6$ \\
Free T4 $(\mathrm{pg} / \mathrm{mL})$ & $10.6 \pm 2.1$ & $10.6 \pm 2.6$ \\
TSH $(\mathrm{mU} / \mathrm{l})$ & $2.2 \pm 0.9$ & $2.3 \pm 2.1$ \\
GH $(\mu \mathrm{g} / \mathrm{L})$ & $0.3 \pm 0.6$ & $0.3 \pm 0.3$ \\
IGF-I $(\mu \mathrm{g} / \mathrm{L})$ & $116.4 \pm 46.9$ & $110.0 \pm 43.6$ \\
DHEA-S $(\mu \mathrm{g} / \mathrm{L})$ & $3.2 \pm 1.6$ & $1.7 \pm 1.0^{* * *}$ \\
OST $(\mu \mathrm{g} / \mathrm{L})$ & $1.2 \pm 0.9$ & $1.6 \pm 2.2$ \\
\hline
\end{tabular}

Abbreviations: BMI, body mass index; OGTT, oral glucose tolerance test; HbA1c, hemoglobin A1c; HOMA-IR, homeostasis model assessment-estimated insulin resistance; FSH, follicle-stimulating hormone; $\mathrm{LH}$, luteinizing hormone; PRL, prolactin; TSH, thyroid-stimulating hormone; GH, growth hormone; IGF-I, insulin-like growth factor-1; DHEA-S, dehydroepiandrosterone sulfate; OST, overnight dexamethasone oral suppression test.

\subsection{Methods}

Each subject underwent anthropometric measurements, routine blood and urine analysis, baseline hormone study followed by the oral glucose tolerance test (OGTT), overnight dexamethasone oral suppression test (OST) and dual X-ray absorptiometry (DXA) on separate days and in fasting conditions.

Blood glucose, electrolytes and glycated haemoglobin $(\mathrm{HbA} 1 \mathrm{c})$ were measured by enzymatic methods (Roche Molecular Biochemicals, Mannheim, Germany). A two-site, solid-phase chemiluminescent immunometric assay or competitive immunoassay was used for insulin, FSH, LH, FT4, TSH, GH, PRL, IGF-I, estradiol, testosterone, cortisol, DHEAS, osteocalcin and PTH levels (Immulite 2000 Analyzer; DPC, Los Angeles, CA, USA). Chemiluminescence was used for measurement of bone alkaline phosphatase (BAP) with intra and interassay coefficients of variation (CVs) of $4 \%$ and $6.1 \%$, respectively (Liaison Bap Ostase, Diasorin, Stillwater, MN, USA); and carboxy-terminal telopeptide of 
type I collagen (CTX), with intra and interassay CVs of 3.5\% and 2.2\% (Elecsys, Roche Diagnostics GmbH, Mannheim, Germany). Enzyme immunoassays were used for measurement of urine amino-terminal collagen cross-links (NTX), with intra and interassay CVs of $4.6 \%$ and $6.9 \%$ (Wampole Laboratories, Princetown, NJ, USA); sclerostin levels, with intra and interassay CVs of $5 \%$ and $3 \%$ (Biomedica; Wien, Austria); osteocalcin levels, with intra and interassay CVs of $3 \%$ and $4 \%$; adiponectin levels, with intra and interassay CVs of 7\% and 8.4\% (DRG Instruments $\mathrm{GmbH}$, Marburg, Germany); leptin levels, with intra- and interassay CVs of $5.9 \%$ and $6.9 \%$ (Linco, St. Louis, MO, USA). Levels of 25OH-Vitamin D were measured using a Cobas Integra 800 Autoanalyzer (Roche, Indianapolis, IN, USA). Upon OGTT, ADA guidelines were applied for glucose tolerance [39] as follows: normal fasting plasma glucose (FPG) if $<100 \mathrm{mg} / \mathrm{dL}(5.6 \mathrm{mmol} / \mathrm{L})$; impaired FPG if 100-125 mg/dL (6.9 mmol/L); impaired glucose tolerance (IGT) if $2 \mathrm{~h}$ OGTT-PG 140-199 mg/dL (7.8-11.0 mmol/L); T2DM if FPG > $126 \mathrm{mg} / \mathrm{dL}$ (7 mmol/L) on two days apart or if 2-h OGTT-PG > $200 \mathrm{mg} / \mathrm{dL}(>11.1 \mathrm{mmol} / \mathrm{L})$. HbA1C values of 5.7 and $6.4 \%$ were considered as threshold for normal glucose and T2DM, respectively. Insulin resistance was calculated by the homeostatic model of insulin resistance (HOMA-IR) as fasting insulin $(\mu \mathrm{U} / \mathrm{m}) \times[$ fasting PG $(\mathrm{mmol} / \mathrm{L}) / 22.5]$.

\subsection{Bone Mineral Densitometry and Body Composition Analysis}

BMD measurements of the lumbar spine (L1-L4) and proximal femur were undertaken with the Prodigy densitometer (Lunar, Madison, WI, USA). Body composition was measured as derivative values of lean body weight and total body percentage fat. A positioning device was used to facilitate the reproducible measurement of the proximal femur. Quality control by daily measurement of an anthropomorphic spine phantom at each site, calibration with a spine phantom to provide cross-site and cross-time calibrations, and a site-level review of all participant scans for specified criteria. Bone scans were acceptable if there was no radiological interference from truncal adiposity, arm or leg did not overlap, no body parts were outside the scan field or positioning problems due to adiposity, no motion. In the case of the proximal femur, all femur subregions had to be valid in order for data to be retained for any of the subregions. Because the three BMD measures correlated highly with each other, a value of total BMD was incorporated in the analysis by averaging all sites analyzed.

\subsection{Statistical Analysis}

All data are expressed as mean \pm SD. Data were tested for normality of distribution by the Shapiro-Wilk test and log-transformed when needed, to correct for skewness. Differences between pre- and postmenopausal subjects were calculated by two-tailed unpaired $t$ test. Correlations analyses were calculated with the Pearson's coefficient. Inspection of the distributions of the variables indicated that the two groups overlapped. Therefore, to make the correlation analysis numerically more consistent, Pearson correlations were performed on the total 56 subjects to assess relationships among variables. The general linear model and analysis of covariance (ANCOVA) were used to evaluate the interaction between variables after statistically controlling for the effects of menopause; effect sizes and interactions were computed between variables and the covariate. Non-collinear independent predictors were included in a stepwise multiple regression model, as described in the results section. For significance, $p<0.05$ was considered of statistical value. Analyses were performed with the SPSS 21.0 (SPSS, Inc., Chicago, IL, USA).

\section{Results}

Table 1 illustrates the large set of bone/adipose tissue markers analyzed in this study. With the exception of the expected differences in menopause-related hormones, menopause did not significantly alter the hormone profiles investigated herein, while adiponectin levels were higher after menopause possibly due to an age-related effect. In terms of glucose metabolism, premenopausal and postmenopausal women with obesity 
exhibited comparable rates of IFG (53.5\% vs. 35.7\%), IGT (35.7\% vs. $32.1 \%)$ and T2DM (25\% for both).

Analysis of bone-related parameters only revealed between-group differences in CTX and NTX levels while sclerostin levels showed a trend toward an increase after menopause (Table 2$)$. The rate of vitamin D deficiency $(<20 \mathrm{mcg} / \mathrm{L})$ was similar between pre- and postmenopausal women $(92.8 \%$ vs. $96.4 \%)$. In women with newly diagnosed T2DM, we documented lower levels of osteocalcin (3.8 \pm 2.1 vs. $6.7 \pm 3.7 \mu \mathrm{g} / \mathrm{L}, p<0.01), \mathrm{CTX}(234 \pm 89.1$ vs. $376.9 \pm 140.3 \mathrm{pg} / \mathrm{mL}, p<0.01)$ and NTX levels $(27.2 \pm 7.8$ vs. $37.6 \pm 15.9 \mathrm{nM} / \mathrm{BCE}$, $p<0.05)$ as compared to their non-diabetic counterpart.

Table 2. Bone-related biochemical and hormone parameters measured in the study groups. Significance was calculated by two-tailed unpaired Student $t$ test. For significance: ${ }^{* *} p<0.01 ;{ }^{* *} p<0.001$.

\begin{tabular}{|c|c|c|}
\hline Parameters & $\begin{array}{l}\text { Premenopausal Women } \\
\qquad(\mathbf{N}=\mathbf{2 8})\end{array}$ & $\begin{array}{l}\text { Postmenopausal Women } \\
\qquad(\mathrm{N}=28)\end{array}$ \\
\hline Calcium (mg/dL) & $9.0 \pm 0.4$ & $9.1 \pm 0.5$ \\
\hline Phosphate (mg/dL) & $3.7 \pm 0.5$ & $3.8 \pm 0.6$ \\
\hline $\mathrm{CTX}(\mathrm{pg} / \mathrm{mL})$ & $293.6 \pm 103.7$ & $399.1 \pm 160.9^{* * *}$ \\
\hline $\operatorname{NTX}(\mathrm{nM} / \mathrm{BCE})$ & $28.7 \pm 10.5$ & $41.3 \pm 16.4^{* * *}$ \\
\hline $\mathrm{BAP}(\mu \mathrm{g} / \mathrm{L})$ & $13.2 \pm 6.0$ & $20.9 \pm 22.4^{* *}$ \\
\hline PTH $(\mu \mathrm{g} / \mathrm{L})$ & $74.6 \pm 28.2$ & $74.4 \pm 34.9$ \\
\hline $25 \mathrm{OH}$-vitamin D $(\mu \mathrm{g} / \mathrm{L})$ & $11.0 \pm 7.4$ & $9.6 \pm 7.2$ \\
\hline Sclerostin (pmol/l) & $18.1 \pm 6.3$ & $21.4 \pm 8.6$ \\
\hline Osteocalcin $(\mu \mathrm{g} / \mathrm{L})$ & $5.6 \pm 3.4$ & $6.3 \pm 3.8$ \\
\hline
\end{tabular}

Abbreviations: CTX, carboxy-terminal telopeptide of type I collagen; NTX, urine amino-terminal collagen crosslinks; $\mathrm{BAP}$, bone alkaline phosphatase; $\mathrm{PTH}$, parathormone.

DXA scanning revealed lower lean mass and higher fat mass in postmenopausal as compared to premenopausal women. Lumbar spine BMD was similar between groups, while lower BMD values at the total hip $\left(-0.138 \mathrm{~g} / \mathrm{cm}^{2}\right)$, femoral neck $\left(-0.147 \mathrm{~g} / \mathrm{cm}^{2}\right)$ and total skeleton $\left(0.210 \mathrm{~g} / \mathrm{cm}^{2}\right)$ were documented in postmenopausal women compared to premenopausal ones (Table 3). BMD values suggestive of osteoporosis were only observed at the lumbar spine in one premenopausal woman.

Table 3. Dual X-ray absorptiometry (DXA) parameters measured in the study groups. Significance was calculated by two-tailed unpaired Student's $t$-test. For significance: ${ }^{*} p<0.05 ;{ }^{* * *} p<0.001$.

\begin{tabular}{|c|c|c|}
\hline Parameters & $\begin{array}{l}\text { Premenopausal Women } \\
(\mathbf{N}=\mathbf{2 8})\end{array}$ & $\begin{array}{l}\text { Postmenopausal Women } \\
\qquad(\mathrm{N}=28)\end{array}$ \\
\hline Lumbar spine BMD $\left(\mathrm{g} / \mathrm{cm}^{2}\right)$ & $1.232 \pm 0.147$ & $1.194 \pm 0.173$ \\
\hline Hip BMD $\left(\mathrm{g} / \mathrm{cm}^{2}\right)$ & $1.148 \pm 0.146$ & $1.010 \pm 0.118^{* * *}$ \\
\hline Femoral neck BMD $\left(\mathrm{g} / \mathrm{cm}^{2}\right)$ & $1.060 \pm 0.130$ & $0.917 \pm 0.104^{* * *}$ \\
\hline Total body BMD $\left(\mathrm{g} / \mathrm{cm}^{2}\right)$ & $1.272 \pm 0.072$ & $1.190 \pm 0.109^{* * *}$ \\
\hline $\mathrm{BMC}(\mathrm{g} / \mathrm{cm})$ & $2.345 \pm 0.434$ & $2.135 \pm 0.365$ \\
\hline Lean body mass (kg) & $53.2 \pm 5.1$ & $49.7 \pm 6.7^{*}$ \\
\hline Fat body mass $(\%)$ & $51.7 \pm 3.3$ & $53.2 \pm 3.1$ \\
\hline
\end{tabular}

Abbreviations: BMD, bone mineral density; BMC, bone mineral content.

In correlation analysis (Table 4, Figure 1), sclerostin was associated with NTX and testosterone levels, as well as with lumbar spine BMD and skeletal BMC, while an expected inverse association related estradiol with NTX $(r=-373, p<0.01)$ and CTX levels $(\mathrm{r}=-290$, $p<0.05)$. Lean mass clearly elicited a protective effect on BMD at the femoral neck $(\mathrm{r}=0.301$, $p<0.05)$, total hip $(\mathrm{r}=0.290, p<0.05)$ as well as total body $(\mathrm{r}=0.499, p<0.001)$. ANCOVA showed that a poor interaction between lean mass and menopause on total BMD $(\mathrm{F}=0.6$, not significant). 
Table 4. Bivariate correlation analysis between sclerostin levels and the main variables of interest in the groups as a whole. Pearson's correlation coefficient and 2-tailed significance are shown for each variable, with significant associations in bold.

\begin{tabular}{ccc}
\hline Variables & \multicolumn{2}{c}{ Sclerostin (pmol/L) } \\
\cline { 2 - 3 } & $\mathbf{r}$ & $\mathbf{p}$ \\
\hline BMD_LS & $\mathbf{0 . 4 7 2}$ & $\mathbf{0 . 0 0 1}$ \\
BMD_TH & 0.110 & 0.455 \\
BMD_FN & 0.079 & 0.594 \\
BMD_TB & 0.186 & 0.206 \\
BMC & $\mathbf{0 . 3 6 1}$ & $\mathbf{0 . 0 1 3}$ \\
\%FBM & 0.016 & 0.915 \\
LBM & 0.008 & 0.955 \\
BMI & -0.017 & 0.903 \\
Estradiol $(\mu \mathrm{g} / \mathrm{L})$ & -0.090 & 0.531 \\
Testosterone $(\mu \mathrm{g} / \mathrm{L})$ & $-\mathbf{0 . 2 9 0}$ & $\mathbf{0 . 0 4 1}$ \\
25OH-vitamin D $(\mu \mathrm{g} / \mathrm{L})$ & 0.088 & 0.533 \\
PTH $(\mu \mathrm{g} / \mathrm{L})$ & -0.267 & 0.053 \\
BAP $(\mu \mathrm{g} / \mathrm{L})$ & 0.050 & 0.735 \\
CTX $(\mathrm{pg} / \mathrm{mL})$ & 0.210 & 0.161 \\
NTX (nM/BCE) & $\mathbf{0 . 3 1 7}$ & $\mathbf{0 . 0 2 8}$ \\
Osteocalcin $(\mu \mathrm{gg} / \mathrm{L})$ & 0.003 & 0.981 \\
HOMA-IR & -0.206 & 0.138 \\
Leptin $(\mu \mathrm{g} / \mathrm{L})$ & 0.081 & 0.565 \\
\hline
\end{tabular}

Abbreviations: BMD, bone mineral density; BMD_LS, BMD at the lumbar spine; BMD_TH, BMD at the total hip; BMD_FN, BMD at the femoral neck; BMD_TB, total body BMD; \%FBM, percent fat body mass; LBM, lean body mass; BMI, body mass index; $\mathrm{PTH}$, parathormone; BAP, bone alkaline phosphatase; CTX, carboxy-terminal telopeptide of type I collagen; NTX, urine amino-terminal collagen cross-links; HOMA-IR, homeostasis model assessment-estimated insulin resistance.
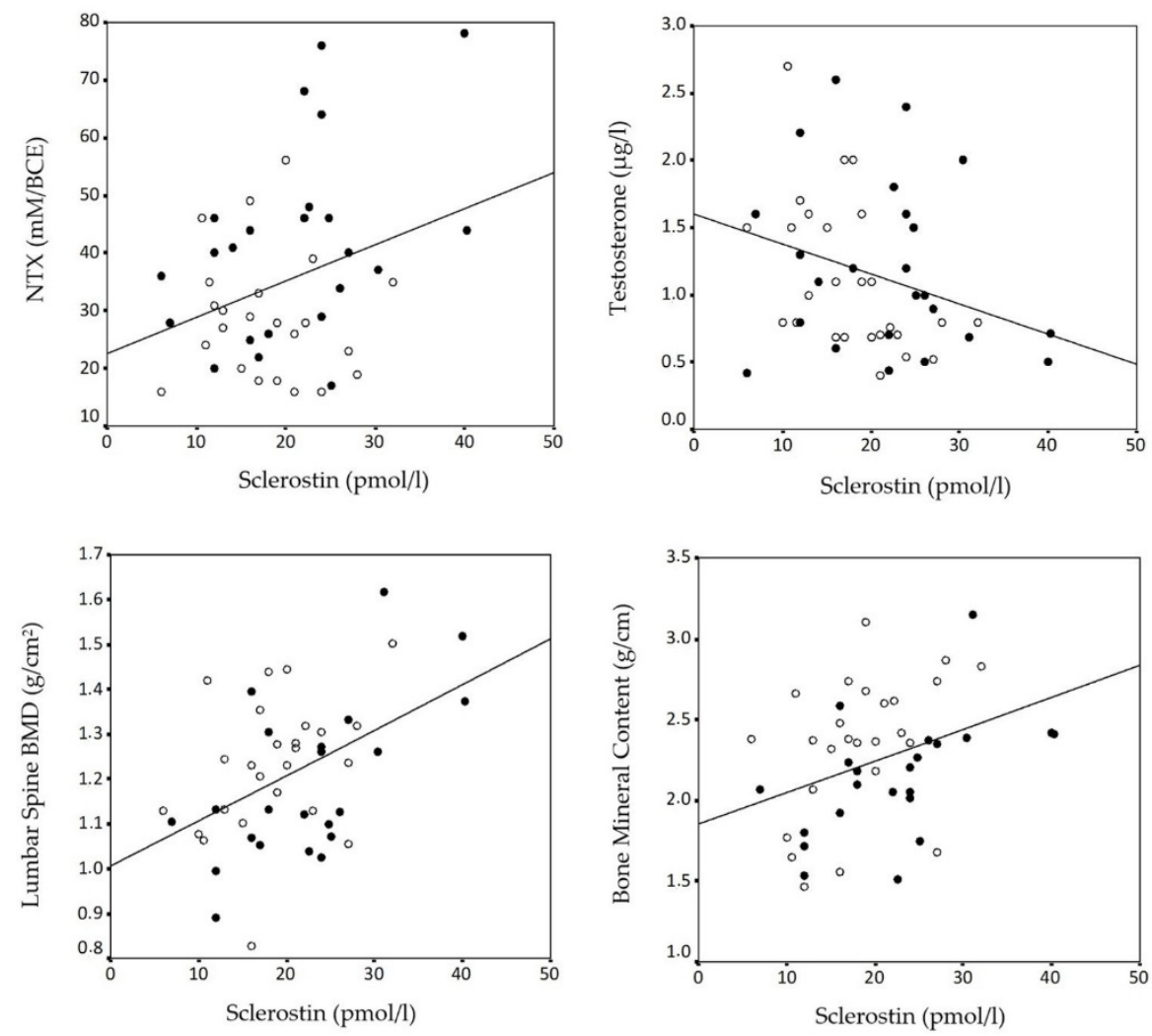

Figure 1. Bivariate correlation analysis between sclerostin levels (pmol/L) and NTX levels (mM/BCE), testosterone levels $(\mu \mathrm{g} / \mathrm{L})$, Lumbar Spine BMD $\left(\mathrm{g} / \mathrm{cm}^{2}\right)$ and BMC $(\mathrm{g} / \mathrm{cm})$ in premenopausal (open circles) and postmenopausal obese women (closed circles). 
As shown in Table 5, a multivariable model was built to test the role of hormone and adiposity markers on sclerostin levels and bone health. Sclerostin emerged as the strongest predictor of BMD at the lumbar spine. In turn, testosterone levels and menopause explained about $40 \%$ in the variability of sclerostin levels. As expected, menopause significantly predicted BMD at the femoral neck, total hip and total body. Similar correlations were obtained when estradiol levels replaced as a continuous variable the dichotomic menopausal status. Finally, lean body mass emerged as the strongest predictor of total BMD.

Table 5. Multivariable regression analysis in merged study groups. Results are provided for variables in the regression equation, adjusted $\mathrm{R}^{2}$ values for significant predictors, standardized coefficients $(\beta)$ and $p$ values, with significant associations shown in bold character. For menopause: $0=$ no, 1 = yes. For significance: ${ }^{*}, p<0.05 ;{ }^{* *}, p<0.01,{ }^{* * *}, p<0.001$.

\begin{tabular}{|c|c|c|c|c|c|c|}
\hline \multirow{3}{*}{ Variables } & Sclerostin & $\begin{array}{c}\text { Lumbar } \\
\text { Spine BMD }\end{array}$ & $\begin{array}{c}\text { Femoral } \\
\text { Neck BMD }\end{array}$ & $\begin{array}{c}\text { Total } \\
\text { Hip BMD }\end{array}$ & $\begin{array}{c}\text { Total } \\
\text { Body BMD }\end{array}$ & $\begin{array}{c}\text { Total } \\
\text { Body BMC }\end{array}$ \\
\hline & \multicolumn{6}{|c|}{$\beta$ Value } \\
\hline & $\left(a R^{2}, 0.390\right)$ & $\left(a R^{2}, 0.351\right)$ & $\left(a R^{2}, 0.374\right)$ & $\left(a R^{2}, 0.373\right)$ & $\left(a R^{2}, 0.481\right)$ & $\left(a R^{2}, 0.345\right)$ \\
\hline Sclerostin & - & $0.573 * *$ & 0.262 & 0.209 & 0.250 & $0.472 * *$ \\
\hline Menopause & $0.395 * *$ & -0.174 & $-0.561^{* * *}$ & $-0.454^{* *}$ & $-0.344 *$ & $-0.357 *$ \\
\hline Testosterone & $-0.428 * *$ & 0.117 & 0.080 & 0.012 & -0.030 & 0.040 \\
\hline РTH & -0.191 & -0.142 & 0.010 & -0.155 & -0.055 & 0.011 \\
\hline Osteocalcin & 0.149 & -0.124 & -0.172 & -0.185 & -0.290 & -0.037 \\
\hline LBM & 0.160 & 0.085 & 0.150 & 0.177 & $0.353 * *$ & -0.122 \\
\hline HOMA-IR & -0.206 & 0.111 & 0.002 & 0.062 & 0.050 & -0.123 \\
\hline Leptin & 0.061 & -0.196 & 0.075 & 0.019 & 0.046 & -0.289 \\
\hline
\end{tabular}

For abbreviations: aR2, adjusted R2; BMD, bone mineral density; BMC, bone mineral content; PTH, parathormone; LBM, lean body mass; HOMA-IR, homeostasis model assessment-estimated insulin resistance.

We then assessed the determinants of circulating sclerostin in our obese cohort. Figure 2 presents $\eta^{2}$ values that explain how much (the percentage) each variable contributed to the total variability in sclerostin levels. Testosterone levels and menopause explained the highest impact accounting together for $70 \%$ of circulating sclerostin variability, while a modest influence was observed for HOMA-IR and PTH concentrations.

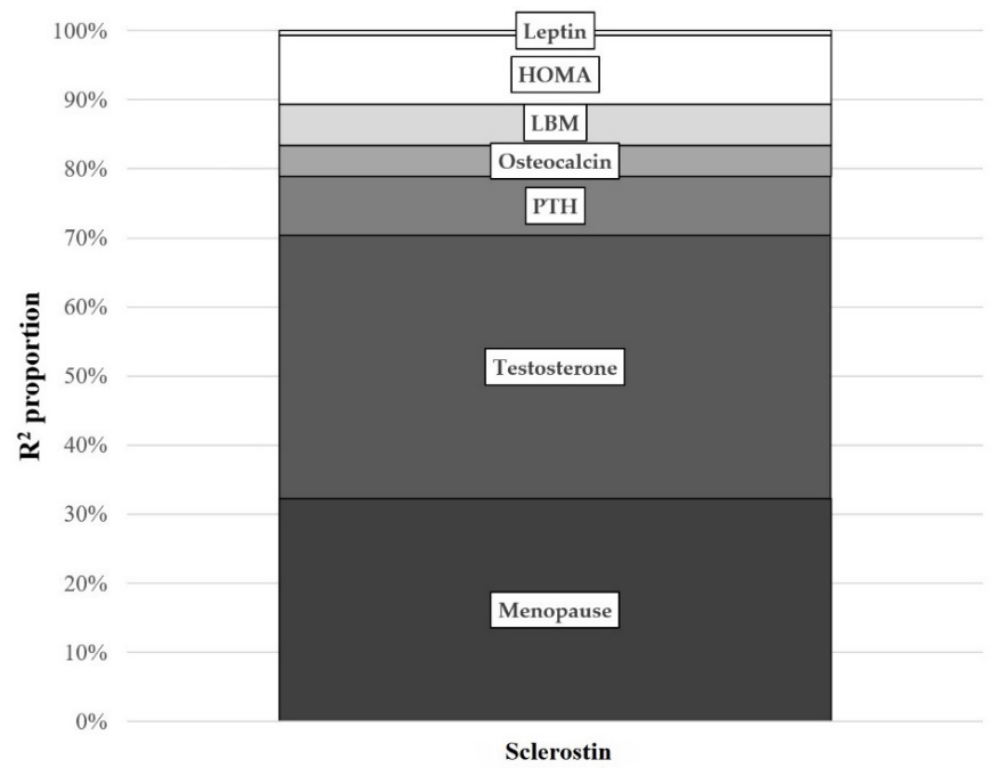

Figure 2. Total variance proportion ( $\mathrm{R}^{2}$ proportion) observed for each variable with the use of an univariate analysis of variance in sclerostin prediction model according to $\eta^{2}$ values. 


\section{Discussion}

This comprehensive study conducted in severely obese women distinguished by menopause provides evidence that obesity does not associate with (early) postmenopausal bone loss at the lumbar spine, with sclerostin acting as the strongest protective determinant at this site. By contrast, menopause associates with unfavorable changes in femoral BMD, with the protective effect of lean mass being predominant at this site. Site-specific relations between obesity and bone health hence provide evidence of peculiar biochemical and anatomical determinants for such effects.

Menopause causes bone loss in some women more rapidly than in others. High body weight and BMI putatively act on bone composition and fracture risk protectively, with rates of spine and hip bone loss reported to be $35-55 \%$ lower in postmenopausal women having their body weight in the top tertile than those at the lowest tertile [40]. Potential explanatory mechanisms reside in extraovarian contribution of estradiol from aromatase activity in fat tissue [41] and mechanical loading effect caused by weight excess, which stimulates proliferation and differentiation of osteoblasts and osteocytes through the $W n t / \beta$-catenin pathway $[42,43]$. However, considering that the degree of physical activity is less consistent in obese women, as it generally is in the postmenopausal state, it should be considered that obese women may be more exposed to peripheral fractures, given the prominent weight-bearing activity of the spine. Increasing credit is given to the suggestion that adiposity actually impairs bone health due to direct and indirect mechanisms relating to decreased ostoblastogenesis and increased adipogenesis [44]; increased osteoclast activity through proinflammatory cytokines and RANKL/RANK/OPG pathway [45], which regulates osteoclast formation, activation and survival in normal bone modeling and in a variety of pathologic conditions characterized by increased bone turnover [46]; degenerative and inflammatory disorders of the musculo-skeletal system [47]; excess in fat intake interfering with intestinal calcium absorption [48]; altered vitamin D and PTH status [15]. Furthermore, fat deposition in vertebral bone marrow influences bone mass and fracture risk [49]. In pre-and postmenopausal cohorts, fat mass has been found inversely associated with BMD and correlated with non-spine fractures, when body weight is kept constant [50]. Also, obesity increased the incidence of ankle and upper leg fractures in postmenopausal women [8]. Finally, sarcopenic obesity with a predominant visceral phenotype has been found associated with a greater fracture risk, in addition to promote proinflammatory and dysmetabolic changes [51]. In this comprehensive study, we examined: (1) the overall effect of early menopause on bone density in relation to metabolic and hormonal profiles linked to obesity and bone health; (2) the involvement of sclerostin in specific-site mineral content; and (3) the role of body composition on bone health across menopause.

Bone density and metabolism: In perimenopausal women, BMD of the radius, femoral neck, and spine declines progressively [40]. Parallel results have been underscored in women spanning a wide age range, where postmenopausal bone loss was found to be significant, both at the lumbar spine and hip [52] but more so at the Ward's triangle [53]. The Study of Women's Health Across the Nation (SWAN) outlined an accelerated bone loss during 1 year preceding and 2 years following the final menses at the lumbar spine, where BMD decreased by $3.2-5.6 \%$ in the late perimenopause and after menopause [54], respectively, while milder bone loss was observed at the hip $[40,54]$. In the present series, postmenopausal obesity did not change lumbar spine BMD, while it associated with a $12 \%$ and 13\% lower BMD at the hip and femoral neck, respectively, as compared to the premenopausal state. Given the coordinated changes seen in bone-specific markers, anabolic hormones and lean mass, this site-specific effect of (early) menopause in obesity suggest an impairment in cortical porosity and cortical thickness as the potential consequence of menopause in obesity. These changes may alter the mechanosensory properties of bone tissue and local tissue repair responses, which progress to microdamage with aging [55], a circumstance that is consistent with the higher rates of ankle and upper leg (fragility) fractures seen in postmenopausal obesity [8,9]. Biochemical dynamics consistent with increased bone turnover in menopause involved increments in circulating CTX and NTX. 
Such increase, which has been already seen in obesity [35,56], predicts the rate of bone loss in postmenopausal women and the risk of osteoporosis in elderly women [57]. Collagen telopeptides were also related to osteocalcin, a non-collagen protein of bone matrix and one of the osteoblast-specific proteins, which was in turn oppositely associated to total body BMD. This relationship extends to obesity the role of osteocalcin as a marker of bone turnover rather than a specific marker of bone formation, as it functions to limit bone formation without impairing bone resorption or mineralization [58]. In our hands, an inverse association related osteocalcin and glucose metabolism, which could agree with the antagonizing effect of osteocalcin on hyperglycemia and $\beta$-cell dysfunction [59] and substantiate the converging effect of dysmetabolic changes of obesity with bone health. As such, a negative association related insulin resistance to $B M C$, which agrees with evidence of increasing insulin resistance across with decreasing BMC [4]. Insulin resistance may thus reflect a cardinal pathway promoting lower bone strength and increased risk of fracture in patients with diabetes mellitus $[6,19]$.

Sclerostin and bone-regulating hormones: Being a factor that promotes bone resorption, we evaluated sclerostin and its regulation operated by perimenopausal hormone status so as to identify potential modulators of bone status in obesity. Previous studies found that sclerostin levels increase with age [60], menopause [61], insulin resistance and type 2 diabetes mellitus [34], while a debated association with obesity exists [35]. In our population, mean sclerostin levels were slightly increased in postmenopausal women, a finding that agrees with studies showing that sclerostin progressively increases after menopause [62]. With regard to sex steroids, it is known that estrogens suppress circulating and bone sclerostin mRNA levels while an opposite role has been observed for testosterone both in experimental and clinical studies $[30,63,64]$. In our hands, there was no association between estradiol and sclerostin levels while, surprisingly, sclerostin decreased with increasing testosterone. As such, menopause (positively) and testosterone (negatively) largely predicted sclerostin variability in multivariable regression analysis. We speculate that the negative control exerted by testosterone on sclerostin levels is peculiar of obesity and likely due to enhanced fat-derived androgen aromatization. It is known that obesity associates with variable androgen excess throughout the lifespan both in preand post-menopausal women, which does not often manifest with specific clinical signs or symptoms and originates from changes in the pattern of secretion and/or metabolism, transport, and/or local action of androgens [65-67]. With regard to bone health, sclerostin levels were found to be positively associated with lumbar spine BMD, a finding that was confirmed in multivariable regression analysis. This correlation expands to obesity similar findings previously described in different cohorts [30,32,33,68,69], although it seems to conflict with the positive association between sclerostin and NTX levels seen herein, as well as with the intrinsic osteopenic effects of sclerostin $[26,28]$. Further studies are required to clarify this issue.

Within the comprehensive hormone panel screened in clinical setting, we failed to identify a role for vitamin $\mathrm{D}$, adiponectin and leptin, as well as the somatotroph and thyroid axes, on bone health. Thus, it is conceivable that other peripheral factors, such as body composition, may play a role in bone health in obesity.

Body composition: While lean body mass was decreased in postmenopausal women, percent fat body mass was similar between groups. Total body BMD was directly associated to lean body mass and BMI, whereas the association to body fat was the opposite. Furthermore, lean mass and menopause acted as independent predictors of total body BMD and explained nearly $50 \%$ of its variability. These findings highlight the prevalent role of dynamic biomechanical forces over passive loads on bone composition in obesity. Previous studies in adolescents and young women have linked bone strength to the dynamic loads from muscle force rather than fat mass [70,71]. In Chinese cohorts, the percentage of body fat was related to the risk of osteoporosis, osteopenia, and non-spine fractures independent of body weight [50]. Studies in different ethnicities confirmed that percent fat mass was inversely related to weight-adjusted bone mass after removal of age, 
sex, menopause status, exercise, and smoking [72]. Intriguingly, visceral fat accumulation was found to negatively predict femoral cross-sectional area, cortical bone area, principal moment maximum, principal moment minimum, and polar moment, while subcutaneous acted as a positive correlate [5]. Together, these findings corroborate the link between body fat and limb fractures in obese postmenopausal women.

Caveats of the study: This study has some limitations. Since our investigation included severely obese Caucasian women in the perimenopausal age range, these findings cannot be generalized to other contexts or be extended to all obese women. The study design did not include a control group, due to the obese-restricted analysis of bone metabolism across menopause. Because of the cross-sectional design, any alteration would be random with respect to case status, and could probably underestimate the observed associations. We believe that the strict inclusion criteria and population selection of the study constitute a point of strength. Indeed, a future menopause transition study will appropriately reduce the risk of biased detection. Also, calcium intake and nutritional habits were not taken in appropriate account. Lastly and more notably, DXA has technical limitations in obesity associated with extraosseous soft tissue composition, so that BMD will appear to decrease more slowly in subjects with more soft tissue fat and vice versa [73]. Increased soft-tissue inhomogeneity is likely to occur from a greater and/or more variable amount of visceral fat surrounding the organs and subcutaneous fat around the hips in overweight and obese women. Increased percent body fat increases BMD precision errors, particularly at the lumbar spine and femoral neck regions of interest [74].

\section{Conclusions}

This cross-sectional analysis suggests that obesity protects the lumbar spine from bone loss caused by menopause possibly through pathways involving sclerostin. The positive association seen between total body bone density and lean body mass offers a potential clue for preventive measures against osteoporosis in this setting. Menopause-transition studies are warranted to better discriminate the reasons for such selective changes in obesity.

Author Contributions: Conceptualization, P.M.; methodology, P.M.; validation, C.M., M.S. and G.A.; formal analysis, P.M. and C.M.; investigation, P.M. and S.M.; data curation, S.M.; writing-original draft preparation, P.M.; writing-review and editing, C.M. and M.S.; supervision, A.N. and G.A. All authors have read and agreed to the published version of the manuscript.

Funding: This work was funded by a grant from the Italian Ministry of Health (Progetto di Ricerca Corrente 18C101-2011).

Institutional Review Board Statement: The study was conducted according to the guidelines of the Declaration of Helsinki, and approved by the Institutional Ethics Committee of Istituto Auxologico Italiano (protocol code 18C101_2011).

Informed Consent Statement: Informed consent was obtained from all subjects involved in the study.

Data Availability Statement: The datasets generated during and/or analysed during the current study are available from the corresponding author on reasonable request.

Conflicts of Interest: The authors declare no conflict of interest.

\section{References}

1. Villareal, D.T.; Apovian, C.M.; Kushner, R.F.; Klein, S.; American Society for Nutrition; NAASO, The Obesity Society. Obesity in older adults: Technical review and position statement of the American Society for Nutrition and NAASO, The Obesity Society. Am. J. Clin. Nutr. 2005, 82, 923-934. [CrossRef]

2. Cao, J.J. Effects of obesity on bone metabolism. J. Orthop. Surg. Res. 2011, 6, 30-36. [CrossRef]

3. Janicka, A.; Wren, T.A.; Sanchez, M.M.; Dorey, F.; Kim, P.S.; Mittelman, S.D.; Gilsanz, V. Fat mass is not beneficial to bone in adolescents and young adults. J. Clin. Endocrinol. Metab. 2007, 92, 143-147. [CrossRef]

4. Kim, J.H.; Choi, H.J.; Kim, M.J.; Shin, C.S.; Cho, N.H. Fat mass is negatively associated with bone mineral content in Koreans. Osteoporos. Int. 2012, 23, 2009-2016. [CrossRef]

5. Gilsanz, V.; Chalfant, J.; Mo, A.O.; Lee, D.C.; Dorey, F.J.; Mittelman, S.D. Reciprocal relations of subcutaneous and visceral fat to bone structure and strength. J. Clin. Endocrinol. Metab. 2009, 94, 3387-3393. [CrossRef] 
6. Leidig-Bruckner, G.; Ziegler, R. Diabetes mellitus a risk for osteoporosis? Exp. Clin. Endocrinol. Diabetes 2001, 109, S493-S514. [CrossRef] [PubMed]

7. Greco, E.A.; Fornari, R.; Rossi, F.; Santiemma, V.; Prossomariti, G.; Annoscia, C.; Aversa, A.; Brama, M.; Marini, M.; Donini, L.M.; et al. Is obesity protective for osteoporosis? Evaluation of bone mineral density in individuals with high body mass index. Int. J. Clin. Pract. 2010, 64, 817-820. [CrossRef] [PubMed]

8. Compston, J.E.; Watts, N.B.; Chapurlat, R.; Cooper, C.; Boonen, S.; Greenspan, S.; Pfeilschifter, J.; Silverman, S.; Díez-Pérez, A.; Lindsay, R.; et al. Obesity is not protective against fracture in postmenopausal women: GLOW. Am. J. Med. 2011, 124, 1043-1050. [CrossRef] [PubMed]

9. Premaor, M.O.; Ensrud, K.; Lui, L.; Parker, R.A.; Cauley, J.; Hillier, T.A.; Cummings, S.; Compston, J.E.; Study of Osteoporotic Fractures. Risk factors for nonvertebral fracture in obese older women. J. Clin. Endocrinol. Metab. 2011, 96, 2414-2421. [CrossRef] [PubMed]

10. Reid, R. Relationships among body mass, its components, and bone. Bone 2002, 31, 547-555. [CrossRef]

11. Sadie-Van Gijsen, H.; Crowther, N.J.; Hough, F.S.; Ferris, W.F. The interrelationship between bone and fat: From cellular see-saw to endocrine reciprocity. Cell Mol. Life Sci. 2013, 70, 2331-2349. [CrossRef]

12. Lee, C.G.; Carr, M.C.; Murdoch, S.J.; Mitchell, E.; Woods, N.F.; Wener, M.H.; Chandler, W.L.; Boyko, E.J.; Brunzell, J.D. Adipokines, inflammation, and visceral adiposity across the menopausal transition: A prospective study. J. Clin. Endocrinol. Metab. 2009, 94, 1104-1110. [CrossRef] [PubMed]

13. Messier, V.; Rabasa-Lhoret, R.; Barbat-Artigas, S.; Elisha, B.; Karelis, A.D.; Aubertin-Leheudre, M. Menopause and sarcopenia: A potential role for sex hormones. Maturitas 2011, 68, 331-336. [CrossRef] [PubMed]

14. Frost, H.M. Perspective: On our age-related bone loss: Insights from a new paradigm. J. Bone Miner. Res. 1997, 12, 1539-1546. [CrossRef]

15. Holick, M.F. Vitamin D deficiency. N. Engl. J. Med. 2007, 357, 266-281. [CrossRef]

16. Scacchi, M.; Pincelli, A.I.; Cavagnini, F. Growth hormone in obesity. Int. J. Obes. Relat. Metab. Disord. 1999, 23, 260-271. [CrossRef] [PubMed]

17. Morton, N.M. Obesity and corticosteroids: 11beta-hydroxysteroid type 1 as a cause and therapeutic target in metabolic disease. Mol. Cell Endocrinol. 2010, 316, 154-164. [CrossRef]

18. Marzullo, P.; Minocci, A.; Tagliaferri, M.A.; Guzzaloni, G.; Di Blasio, A.; De Medici, C.; Aimaretti, G.; Liuzzi, A. Investigations of thyroid hormones and antibodies in obesity: Leptin levels are associated with thyroid autoimmunity independent of bioanthropometric, hormonal, and weight-related determinants. J. Clin. Endocrinol. Metab. 2010, 95, 3965-3972. [CrossRef] [PubMed]

19. Ishii, S.; Cauley, J.A.; Crandall, C.J.; Srikanthan, P.; Greendale, G.A.; Huang, M.H.; Danielson, M.E.; Karlamangla, A.S. Diabetes and femoral neck strength: Findings from the Hip Strength Across the Menopausal Transition Study. J. Clin. Endocrinol. Metab. 2012, 97, 190-197. [CrossRef]

20. Crespo, C.J.; Smit, E.; Snelling, A.; Sempos, C.T.; Andersen, R.E.; NHANES III. Hormone replacement therapy and its relationship to lipid and glucose metabolism in diabetic and nondiabetic postmenopausal women: Results from the Third National Health and Nutrition Examination Survey (NHANES III). Diabetes Care 2002, 25, 1675-1680. [CrossRef]

21. Zaidi, M.; Buettner, C.; Sun, L.; Iqbal, J. The link between fat and bone: Does mass beget mass? Endocrinology 2012, 153, 2070-2075. [CrossRef] [PubMed]

22. Upadhyay, J.; Farr, O.M.; Mantzoros, C.S. The role of leptin in regulating bone metabolism. Metabolism 2015, 64, 105-113. [CrossRef] [PubMed]

23. Schwetz, V.; Pieber, T.; Obermayer-Pietsch, B. The endocrine role of the skeleton: Background and clinical evidence. Eur. J. Endocrinol. 2012, 166, 959-967. [CrossRef] [PubMed]

24. Ducy, P. The role of osteocalcin in the endocrine cross-talk between bone remodelling and energy metabolism. Diabetologia 2011, 54, 1291-1297. [CrossRef] [PubMed]

25. Gravenstein, K.S.; Napora, J.K.; Short, R.G.; Ramachandran, R.; Carlson, O.D.; Metter, E.J.; Ferrucci, L.; Egan, J.M.; Chia, C.W. Cross-sectional evidence of a signaling pathway from bone homeostasis to glucose metabolism. J. Clin. Endocrinol. Metab. 2011, 96, 884-890. [CrossRef] [PubMed]

26. Clevers, H. Wnt/beta-catenin signaling in development and disease. Cell 2006, 127, 469-480. [CrossRef] [PubMed]

27. MacDonald, B.T.; Tamai, K.; He, X. Wnt/ $\beta$-catenin signaling: Components, mechanisms, and diseases. Dev. Cell 2009, 17, 9-26. [CrossRef]

28. Barons, R.; Rawadi, G. Targeting the Wnt/beta-catenin pathway to regulate bone formation in the adult skeleton. Endocrinology 2007, 148, 2635-2643. [CrossRef] [PubMed]

29. Balemans, W.; Ebeling, M.; Patel, N.; Van Hul, E.; Olson, P.; Dioszegi, M.; Lacza, C.; Wuyts, W.; Van Den Ende, J.; Willems, P.; et al. Increase bone density in sclerosteosis is due to the deficiency of a novel secreted protein (SOST). Hum. Mol. Genet. 2001, 10, 537-554. [CrossRef]

30. Mödder, U.I.; Hoey, K.A.; Amin, S.; McCready, L.K.; Achenbach, S.J.; Riggs, B.L.; Melton, L.J., 3rd; Khosla, S. Relation of age, gender, and bone mass to circulating sclerostin levels in women and men. J. Bone Miner. Res. 2011, 26, 373-379. [CrossRef] 
31. Gaudio, A.; Pennisi, P.; Bratengeier, C.; Torrisi, V.; Lindner, B.; Mangiafico, R.A.; Pulvirenti, I.; Hawa, G.; Tringali, G.; Fiore, C.E. Increased sclerostin serum levels associated with bone formation and resorption markers in patients with immobilization-induced bone loss. J. Clin. Endocrinol. Metab. 2010, 95, 2248-2253. [CrossRef]

32. Arasu, A.; Cawthon, P.M.; Lui, L.Y.; Do, T.P.; Arora, P.S.; Cauley, J.A.; Ensrud, K.E.; Cummings, S.R.; Study of Osteoporotic Fractures Research Group. Serum sclerostin and risk of hip fracture in older Caucasian women. J. Clin. Endocrinol. Metab. 2012, 97, 2027-2032. [CrossRef]

33. Urano, T.; Shiraki, M.; Ouchi, Y.; Inoue, S. Association of circulating sclerostin levels with fat mass and metabolic disease-related markers in Japanese postmenopausal women. J. Clin. Endocrinol. Metab. 2012, 97, 1473-1477. [CrossRef] [PubMed]

34. García-Martín, A.; Rozas-Moreno, P.; Reyes-García, R.; Morales-Santana, S.; García-Fontana, B.; García-Salcedo, J.A.; MuñozTorres, M. Circulating levels of sclerostin are increased in patients with type 2 diabetes mellitus. J. Clin. Endocrinol. Metab. 2012, 97, 234-241. [CrossRef] [PubMed]

35. Grethen, E.; Hill, K.M.; Jones, R.; Cacucci, B.M.; Gupta, C.E.; Acton, A.; Considine, R.V.; Peacock, M. Serum leptin, parathyroid hormone, 1,25-dihydroxyvitamin D, fibroblast growth factor 23, bone alkaline phosphatase, and sclerostin relationships in obesity. J. Clin. Endocrinol. Metab. 2012, 97, 1655-1662. [CrossRef] [PubMed]

36. Aznou, A.; Meijer, R.; van Raalte, D.; den Heijer, M.; Heijboer, A.; de Jongh, R. Serum sclerostin is negatively associated with insulin sensitivity in obese but not lean women. Endocr. Connect. 2021, 10, 131-138. [CrossRef]

37. Armamento-Villareal, R.; Sadler, C.; Napoli, N.; Shah, K.; Chode, S.; Sinacore, D.R.; Qualls, C.; Villareal, D.T. Weight loss in obese older adults increases serum sclerostin and impairs hip geometry but both are prevented by exercise training. J. Bone Miner. Res. 2012, 27, 1215-1221. [CrossRef]

38. Kim, J.A.; Roh, E.; Hong, S.H.; Lee, Y.B.; Kim, N.H.; Yoo, H.J.; Seo, J.A.; Kim, N.H.; Kim, S.G.; Baik, S.H.; et al. Association of serum sclerostin levels with low skeletal muscle mass: The Korean Sarcopenic Obesity Study (KSOS). Bone 2019, $128,115053$. [CrossRef]

39. American Diabetes Association. Standards of medical care in diabetes-2012. Diabetes Care 2012, 35, S11-S63. [CrossRef]

40. Finkelstein, J.S.; Brockwell, S.E.; Mehta, V.; Greendale, G.A.; Sowers, M.R.; Ettinger, B.; Lo, J.C.; Johnston, J.M.; Cauley, J.A.; Danielson, M.E.; et al. Bone mineral density changes during the menopause transition in a multiethnic cohort of women. J. Clin. Endocrinol. Metab. 2008, 93, 861-868. [CrossRef]

41. Rosen, C.J.; Klibanski, A. Bone, fat, and body composition: Evolving concepts in the pathogenesis of osteoporosis. Am. J. Med. 2009, 122, 409-414. [CrossRef]

42. Ehrlich, P.J.; Lanyon, L.E. Mechanical strain and bone cell function: A review. Osteoporos. Int. 2002, 13, 688-700. [CrossRef]

43. Bonewald, L.F.; Johnson, M.L. Osteocytes, mechanosensing and Wnt signaling. Bone 2008, 42, 606-615. [CrossRef] [PubMed]

44. Rosen, C.J.; Bouxsein, M.L. Mechanisms of disease: Is osteoporosis the obesity of bone? Nat. Clin. Pract. Rheumatol. $2006,2,35-43$. [CrossRef] [PubMed]

45. Pfeilschifter, J.; Köditz, R.; Pfohl, M.; Schatz, H. Changes in proinflammatory cytokine activity after menopause. Endocr. Rev. 2002, 23, 90-119. [CrossRef]

46. Boyce, B.F.; Xing, L. Functions of RANKL/RANK/OPG in bone modeling and remodeling. Arch. Biochem. Biophys. 2008, 473, 139-146. [CrossRef]

47. Anandacoomarasamy, A.; Fransen, M.; March, L. Obesity and the musculoskeletal system. Curr. Opin. Rheumatol. 2009, 21, 71-77. [CrossRef]

48. Wohl, G.R.; Loehrke, L.; Watkins, B.A.; Zernicke, R.F. Effects of high-fat diet on mature bone mineral content, structure, and mechanical properties. Calcif. Tissue Int. 1998, 63, 74-79. [CrossRef]

49. Shen, W.; Chen, J.; Punyanitya, M.; Shapses, S.; Heshka, S.; Heymsfield, S.B. MRI-measured bone marrow adipose tissue is inversely related to DXA-measured bone mineral in Caucasian women. Osteoporos. Int. 2007, 18, 641-647. [CrossRef]

50. Hsu, Y.H.; Venners, S.A.; Terwedow, H.A.; Feng, Y.; Niu, T.; Li, Z.; Laird, N.; Brain, J.D.; Cummings, S.R.; Bouxsein, M.L.; et al. Relation of body composition, fat mass, and serum lipids to osteoporotic fractures and bone mineral density in Chinese men and women. Am. J. Clin. Nutr. 2006, 83, 146-154. [CrossRef] [PubMed]

51. Perna, S.; Spadaccini, D.; Nichetti, M.; Avanzato, I.; Faliva, M.A.; Rondanelli, M. Osteosarcopenic Visceral Obesity and Osteosarcopenic Subcutaneous Obesity, Two New Phenotypes of Sarcopenia: Prevalence, Metabolic Profile, and Risk Factors. J. Aging Res. 2018, 2018, 6147426. [CrossRef] [PubMed]

52. Erdtsieck, R.J.; Pols, H.A.; Algra, D.; Kooy, P.P.; Birkenhäger, J.C. Bone mineral density in healthy Dutch women: Spine and hip measurements using dual-energy X-ray absorptiometry. Neth. J. Med. 1994, 45, 198-205.

53. Ravn, P.; Hetland, M.L.; Overgaard, K.; Christiansen, C. Premenopausal and postmenopausal changes in bone mineral density of the proximal femur measured by dual-energy X-ray absorptiometry. J. Bone Miner. Res. 1994, 9, 1975-1980. [CrossRef]

54. Sowers, M.R.; Jannausch, M.; McConnell, D.; Little, R.; Greendale, G.A.; Finkelstein, J.S.; Neer, R.M.; Johnston, J.; Ettinger, B. Hormone predictors of bone mineral density changes during the menopausal transition. J. Clin. Endocrinol. Metab. 2006, 91, 1261-1267. [CrossRef] [PubMed]

55. Epstein, S. Is cortical bone hip? What determines cortical bone properties? Bone 2007, 41, S3-S8. [CrossRef]

56. Coates, P.S.; Fernstrom, J.D.; Fernstrom, M.H.; Schauer, P.R.; Greenspan, S.L. Gastric bypass surgery for morbid obesity leads to an increase in bone turnover and a decrease in bone mass. J. Clin. Endocrinol. Metab. 2004, 89, 1061-1065. [CrossRef] 
57. Garnero, P.; Delmas, P.D. New developments in biochemical markers for osteoporosis. Calcif. Tissue Int. 1996, 59, S2-S9. [CrossRef] [PubMed]

58. Cloos, P.A.; Christgau, S. Characterization of aged osteocalcin fragments derived from bone resorption. Clin. Lab. 2004, 50, 585-598.

59. Lee, N.K.; Sowa, H.; Hinoi, E.; Ferron, M.; Ahn, J.D.; Confavreux, C.; Dacquin, R.; Mee, P.J.; McKee, M.D.; Jung, D.Y.; et al. Endocrine regulation of energy metabolism by the skeleton. Cell 2007, 130, 456-469. [CrossRef] [PubMed]

60. Xu, Y.; Gao, C.; He, J.; Gu, W.; Yi, C.; Chen, B.; Wang, Q.; Tang, F.; Xu, J.; Yue, H.; et al. Sclerostin and Its Associations With Bone Metabolism Markers and Sex Hormones in Healthy Community-Dwelling Elderly Individuals and Adolescents. Front. Cell Dev. Biol. 2020, 8, 57. [CrossRef]

61. Mirza, F.S.; Padhi, I.D.; Raisz, L.G.; Lorenzo, J.A. Serum sclerostin levels negatively correlate with parathyroid hormone levels and free estrogen index in postmenopausal women. J. Clin. Endocrinol. Metab. 2010, 95, 1991-1997. [CrossRef]

62. Ardawi, M.S.; Al-Kadi, H.A.; Rouzi, A.A.; Qari, M.H. Determinants of serum sclerostin in healthy pre- and postmenopausal women. J. Bone Miner. Res. 2011, 26, 2812-2822. [CrossRef]

63. Drake, M.T.; Khosla, S. Hormonal and systemic regulation of sclerostin. Bone 2017, 96, 8-17. [CrossRef] [PubMed]

64. Mödder, U.I.; Clowes, J.A.; Hoey, K.; Peterson, J.M.; McCready, L.; Oursler, M.J.; Riggs, B.L.; Khosla, S. Regulation of circulating sclerostin levels by sex steroids in women and in men. J. Bone Miner. Res. 2011, 26, 27-34. [CrossRef]

65. Pinkey, J.H.; Kopelman, P.G. Endocrine determinant of obesity. In Handbook of Obesity Etiology and Pathophysiology, 2nd ed.; Bray, G.A., Bouchard, C., Eds.; Marcel Dekker: New York, NY, USA, 2004; pp. 655-670.

66. Kahn, B.B.; Flier, J.S. Obesity and insulin resistance. J. Clin. Investig. 2000, 106, 473-481. [CrossRef] [PubMed]

67. Pasquali, R.; Oriolo, C. Obesity and Androgens in Women. Front. Horm. Res. 2019, 53, 120-134.

68. Amrein, K.; Amrein, S.; Drexler, C.; Dimai, H.P.; Dobnig, H.; Pfeifer, K.; Tomaschitz, A.; Pieber, T.R.; Fahrleitner-Pammer, A. Sclerostin and its association with physical activity, age, gender, body composition, and bone mineral content in healthy adults. J. Clin. Endocrinol. Metab. 2012, 97, 148-154. [CrossRef]

69. Ardawi, M.S.; Rouzi, A.A.; Al-Sibiani, S.A.; Al-Senani, N.S.; Qari, M.H.; Mousa, S.A. High serum sclerostin predicts the occurrence of osteoporotic fractures in postmenopausal women: The CEOR study. J. Bone Miner. Res. 2012, 27, 2592-2602. [CrossRef]

70. Petit, M.A.; Beck, T.J.; Shults, J.; Zemel, B.S.; Foster, B.J.; Leonard, M.B. Proximal femur bone geometry is appropriately adapted to lean mass in overweight children and adolescents. Bone 2005, 36, 568-576. [CrossRef] [PubMed]

71. Wang, M.C.; Bachrach, L.K.; Van Loan, M.; Hudes, M.; Flegal, K.M.; Crawford, P.B. The relative contributions of lean tissue mass and fat mass to bone density in young women. Bone 2005, 37, 474-481. [CrossRef]

72. Zhao, L.J.; Jiang, H.; Papasian, C.J.; Maulik, D.; Drees, B.; Hamilton, J.; Deng, H.W. Correlation of obesity and osteoporosis: Effect of fat mass on the determination of osteoporosis. J. Bone Miner. Res. 2008, 23, 17-29. [CrossRef] [PubMed]

73. Bolotin, H.H.; Sievanen, H.; Grashuis, J.L. Patient-specific DXA bone mineral density inaccuracies: Quantitative effects of nonuniform extraosseous fat distributions. J. Bone Miner. Res. 2003, 18, 1020-1027. [CrossRef] [PubMed]

74. Knapp, K.M.; Welsman, J.R.; Hopkins, S.J.; Fogelman, I.; Blake, G.M. Obesity increases precision errors in dual-energy X-ray absorptiometry measurements. J. Clin. Densitom. 2012, 15, 315-319. [CrossRef] [PubMed] 